EGU21-4424

https://doi.org/10.5194/egusphere-egu21-4424

EGU General Assembly 2021

(c) Author(s) 2021. This work is distributed under

the Creative Commons Attribution 4.0 License.

\title{
Soil texture can predominantly control organic matter mineralization in temperate climates by regulating soil moisture rather than through direct stabilization
}

Haichao Li ${ }^{1}$, Jan Van den Bulcke ${ }^{1}$, Orly Mendoza ${ }^{1}$, Heleen Deroo ${ }^{1}$, Geert Haesaert ${ }^{2}$, Kevin Dewitte ${ }^{2}$, Stefaan De Neve ${ }^{1}$, and Steven Sleutel ${ }^{1}$

1Department of Environment, Ghent University, Belgium (haichao.li@ugent.be)

${ }^{2}$ Department of Plants and Crops, Ghent University, Belgium

Soil organic carbon (OC) levels generally increase with increasing clay and silt content under a similar climatic zone because of increased association of OC to clay minerals and stronger occlusion inside aggregates. Surprisingly though, in Western Europe many silt loam soils actually bear low topsoil OC levels compared to lighter textured soils. Soil texture obviously also strongly controls moisture availability with consequent indirect impact on heterotrophic activity. We hypothesized that with increasingly frequent summer drought: 1) soil microbial activity in sandy soils is more likely impeded due to their limited water holding capacity retention during droughts, while soil OC mineralization in silty soils remain be less drought-limited; 2 ) capillary rise from sufficiently shallow groundwater would, on the other hand, alleviate the water stress in lighter textures. To test these hypotheses, we established a one-year field trial with manipulation of soil texture, monitoring of soil moisture and maize- $\mathrm{C}$ decomposition via ${ }^{13 / 12} \mathrm{C}_{-} \mathrm{CO}_{2}$ emissions. The upper $0.5 \mathrm{~m}$ soil layer was replaced by sand, sandy loam and silt loam soil with low soil OC. Another sandy soil treatment with a gravel layer was also included beneath the sand layer to exclude capillary rise. Soil texture did not affect maize- $C$ mineralization ( $\left.C_{\text {maize }}-\mathrm{min}\right)$ until April 2019 and thereafter $C_{\text {maize }}$-min rates were higher in the silt loam than in the sandy soils $(P=0.01) . \theta_{v}$ correlated positively with the $C_{\text {maize-min }}$ rate for the sand-textured soils only but not for the finer textures. These results clearly highlight that soil texture controlled $C_{\text {maize-min indirectly through }}$ regulating moisture under the field conditions starting from about May, when soils faced a period of drought. By the end of the experiment, more added $C_{\text {maize }}$ was mineralized in the silt loam soil $(81 \%)(P<0.05)$ than in the sandy soil $(56 \%)$. Capillary rise did not result in a significant increase in cumulative $\mathrm{C}_{\text {maize }}$-min in the sandy soil, seemingly because the capillary fringe did not reach the sandy topsoil layer. These results imply that, under future climate scenarios the frequency of drought is expected to increase, the largely unimpeded microbial activity in silty soils might lead to a further stronger difference in soil OC with coarser textured soils under similar management. 